\title{
HYPOMELANOSIS OF ITO
}

\section{Incontinentia Pigmenti Achromians}

\author{
By Sensa Victor P (MD4 2005/2006)
}

\section{INTRODUCTION}

This is a congenital skin disorder which affects children of both sexes and is frequently associated with defects in several organ systems. It was described by Ito in 1951 and other people have subsequently described it. ${ }^{3}$

A child with this disorder presents with bizarre, patterned, hypo-pigmented macules arranged in sharply demarcated whorls, streaks, and patches over the body surface sparing only palms, soles and mucous membranes. This is associated with other physical findings. There is no evidence for genetic transmission and $40 \%$ of patients have chromosomal mosaicism and $60 \%$ have X-chromosome abnormalities. ${ }^{1}$

Approximately $70 \%$ of the reported cases have other associated abnormalities. Seventy percent have associated mental retardation, 40 percent have seizures, 25 percent have cerebral atrophy and 15 percent have muscular hypotonia. The other abnormalities occur in less than $8 \%$ and include microcephaly, coarse facies, abnormal auricles, minor ophthalmologic defects and cardiac defects. ${ }^{2}$

\section{CASE}

H.K is an 18 months old female child, born by spontaneous vaginal delivery with a birth weight of 3.5Kilograms. History of delivery and immediate postnatal care did not suggest birth asphyxia. Antenatal and postnatal periods were uneventful except for a umbilical hernia.

At the age of 2 months she developed hypopigmented skin patch on the fore-head, spreading slowly to involve the whole body by the age of 8 months. There was no history of seizure. She had sought medical care in several health centres before admission at Muhimbili National Hospital.

The developmental milestones were noticeably delayed with neck control around 8 months, sitting with support at 10 months, and failure to sit without support, failure to smile, crawl and stand. On examination, she had generalized streaky hypomelanosis sparing mucous membranes, palms and soles, with $\mathrm{V}$ shaped patterns along the vertebral column. Occipito-frontal circumference was $47.2 \mathrm{~cm}$ (between -2SD and +2SD) with closed anterior fontanel. Weight was $13 \mathrm{Kg}$, length was $85 \mathrm{~cm}$ and the mid-upper arm circumference was $13 \mathrm{~cm}$. These are normal anthropometric measurements.

At diagnosis she was mentally retarded. The formal mental development assessment was not done. But at this stage she was unable to say more than a few words such as $D a$, $\mathrm{Ma}, \mathrm{Ba}$ and $\mathrm{Ka}$. The face was normal, all limbs were hypotonic and the deep tendon reflexes were essentially normal.

CT scan showed just a mild hydrocephalous, otherwise everything else was normal. Despite the fact that the electroencephalogram (ECG) and cranial ultrasound were not done, symptoms and signs were highly suggestive of Hypomelanosis of Ito.

\section{DISCUSSION}

Patients with hypomelanosis of Ito appear to have two genetically distinct cell lines. The chromosome anomalies that have been observed involve both autosomes and sex chromosomes and have been demonstrated in about $50 \%$ of cases. It is considered to be a heterogeneous mosaic condition which occurs sporadically. There is no history of consanguinity.

The condition can be confused with other skin problems such as systematized nevus depigmentosus, which is a stable leukoderma not associated with systemic manifestations. Differentiation from Incontinentia pigmenti, particularly the hypo-pigmented fourth stage, is critical for genetic counselling because Incontinentia Pigmenti, unlike hypomelanosis of Ito, is inherited. Tuberous sclerosis and Linear and Nevoid hypermelanosis should form special differential diagnosis.

Despite the poor prognosis of the child due to the extent of delay of gross motor, fine motor, speech and language and social milestone the mother was counselled that 


\section{DMSJ Vol. 14 No. 2}

the hypo-pigmentation might remain unchanged throughout childhood but fades during adulthood and her survival was expected to be normal.

\section{REFERENCES}

1. Nelson Text book of paediatrics $17^{\text {th }}$ edition pg $2180-2181$
2. Massawe A, Manji K. case report of a Child with hypomelanosis of Ito. Tanzania Medical Journal March 2002, Vol 17, 1:1-3

3. http://www.emedicine.com/ped/topic1 123.htm. 